\title{
Spot size transformer with a type-B antiresonant reflecting optical waveguide
}

\author{
Yasuo Kokubun, Shuichi Tamura, and Tatsumasa Kondo \\ Faculty of Engineering, Division of Electrical and Computer Engineering, Yokohama National University, \\ 156 Tokiwadai, Hodogayaku, Yokohama, 240 Japan
}

Received August 5, 1992

\begin{abstract}
A type-B antiresonant reflecting optical waveguide was incorporated into a spot size transformer to achieve precise control of the spot size without precise control of the refractive index. Owing to the optimum design, a low insertion loss of $0.9 \mathrm{~dB}$ and a large transformation ratio of 5.6 were successfully obtained.
\end{abstract}

In monolithic photonic integrated circuits, a spot size transformer is indispensable for interconnecting with low loss many photonic devices that have different spot sizes. Thus far, several types of spot size transformer, fabricated by photopolymerization, ${ }^{1}$ flame-hydrolysis deposition, ${ }^{2}$ ion-exchange diffusion, ${ }^{3}$ selective growth of semiconductor film by molecularbeam epitaxy, ${ }^{4}$ and step-tapered core structure,${ }^{5}$ have been reported. However, the transformation ratio of these spot size transformers (except the last one) was not large enough, and the loss of the last one is comparatively large.

On the other hand, we have proposed a dualtapered waveguide-type spot size transformer ${ }^{6}$ and demonstrated a low loss and a wide range of transformation ratios (5 to $1 / 5)$. However, this structure requires precise control of the refractive index in the waveguide having the large spot size, because the index difference between the core and the cladding must be very small (approximately 0.15\%) to satisfy the single-mode condition. Generally speaking, it is difficult to control the refractive index precisely by thin-film deposition techniques such as the sputtering technique. Thus the controllability of the spot size was not precise enough owing to the ambiguity of the index difference.

In this Letter we propose a new structure of spot size transformer that uses the type- $B$ antiresonant reflecting optical waveguide ${ }^{7}$ (ARROW-B), as shown in Fig. 1, to solve this problem. In this spot size transformer, an ARROW-B is used as the waveguide having the large spot size. ARROW-B has an interference cladding that consists of two layers; one is the first cladding layer that has a smaller index than the core, and the other is the second cladding layer that has the same index as the core. The greatest advantage in the use of ARROW-B is that precise index control is not needed. Thus we can determine the spot size by controlling only the thickness of the core, and the thickness of the cladding is much thinner than that of conventional waveguides.

First, we performed the optimum design of the new spot size transformer under the following concept. For the three-layer waveguide having the smaller spot size, the thickness of the core was designed to have the minimum spot size. The materials of the core and cladding were assumed to be NA45 glass (whose composition is the same as C7059 glass) and $\mathrm{SiO}_{2}$, respectively, as shown in Fig. 1. The index of NA45 glass is 1.543 , and that of $\mathrm{SiO}_{2}$ is 1.464 , at the wavelength of $0.633 \mu \mathrm{m}$. The index difference is $5.0 \%$. To make the experiment easy, the wavelength of $0.633 \mu \mathrm{m}$ is adopted. The same design concept is also applicable to the other wavelengths. Figure 2 shows the calculated result of spot size $w$ against the thickness of the core $2 a . \Delta$ is $5.0 \%$, and the refractive index of core $n_{c}$ is 1.543 (NA45 glass). The spot size takes its minimum value when the thickness of the core is $0.44 \mu \mathrm{m}$ (more generally, when $a / \lambda=$ $0.17 / n_{c} \sqrt{2 \Delta}$, the normalized spot size $w / \lambda$ takes its minimum value given by $w / \lambda=0.34 / n_{c} \sqrt{2 \Delta}$ ). Thus the thickness of the core of the three-layer waveguide was designed to be $0.44 \mu \mathrm{m}$.

The spot size of ARROW-B was designed to be the same as that of a single-mode fiber at the wavelength of $0.633 \mu \mathrm{m}$, which is approximately $2-2.5 \mu \mathrm{m}$. Thus we designed the spot size of ARROW-B to be $2.4 \mu \mathrm{m}$. The spot size of ARROW-B is proportional to the core thickness and is expressed by $w \approx d_{c} / \pi$ (see Ref. 8 ). Thus the core thickness of ARROW-B is designed to be $7.5 \mu \mathrm{m}$. In addition, the thickness of each cladding layer should be designed to achieve single-mode propagation, that is, the $\mathrm{TE}_{0}$-mode loss is as low as possible, and $\mathrm{TE}_{1}$ and $\mathrm{TE}_{2}$-mode losses are as high as possible. In this study, the propagation loss of the fundamental mode was designed to be $0.1 \mathrm{~dB} / \mathrm{cm}$, and those of other higher-order modes are larger than $5 \mathrm{~dB} / \mathrm{cm}$. Figure 3 shows the propagation losses of $\mathrm{TE}_{0}, \mathrm{TE}_{1}$, and $\mathrm{TE}_{2}$ modes against the thickness of second

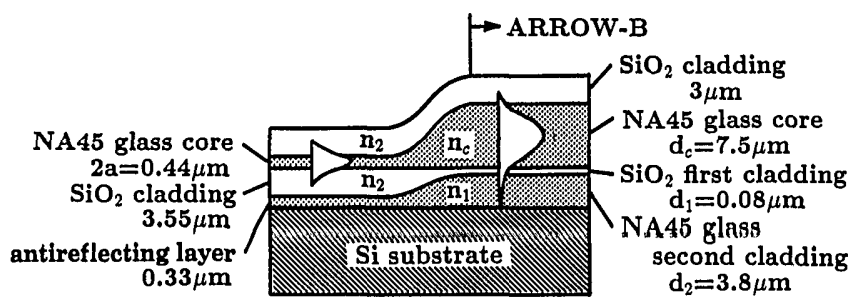

Fig. 1. Spot size transformer with ARROW-B. 


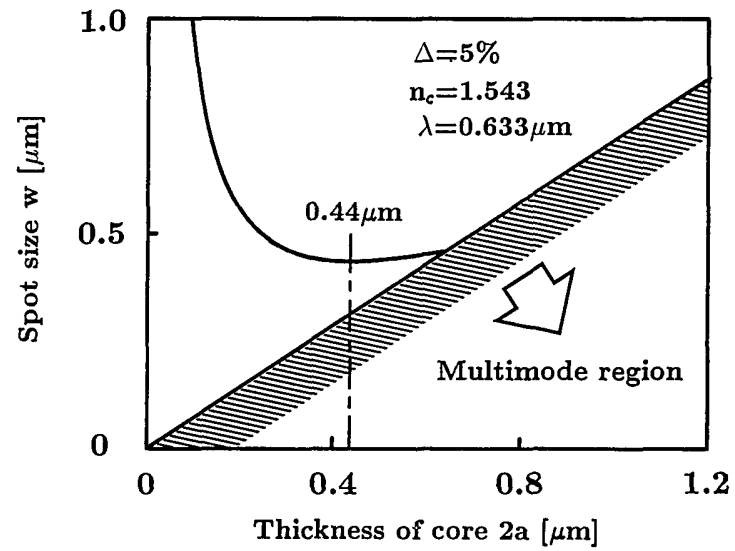

Fig. 2. Spot size versus the thickness of the core of the three-layer slab waveguide.

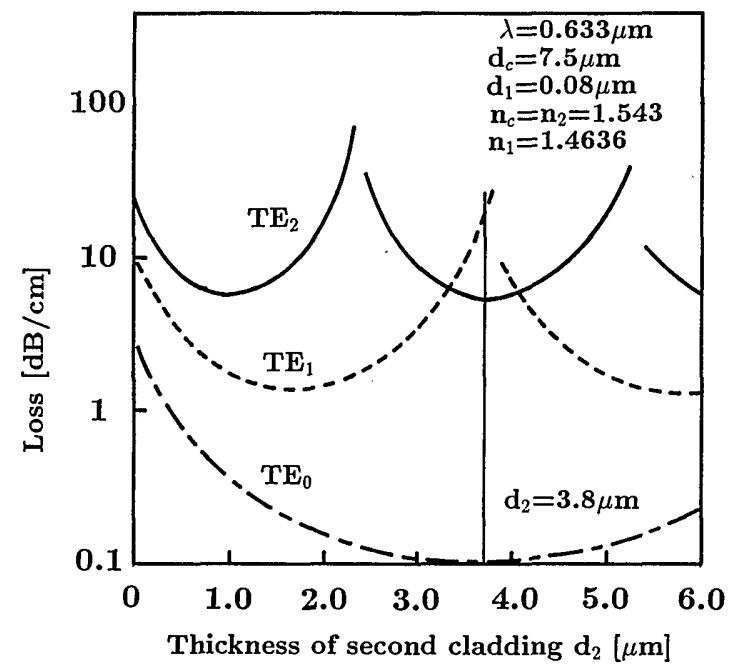

Fig. 3. Propagation losses of $\mathrm{TE}_{0}, \mathrm{TE}_{1}$, and $\mathrm{TE}_{2}$ modes versus the thickness of the second cladding layer of ARROW-B.

cladding $d_{2}$ when the thicknesses of the core and the first cladding are 7.5 and $0.08 \mu \mathrm{m}$, respectively. The $\mathrm{TE}_{0}$-mode loss is minimum at $d_{2}=3.8 \mu \mathrm{m}$, and the $\mathrm{TE}_{2}$-mode loss is lower than that of the $\mathrm{TE}_{1}$ mode. Since the loss of higher-order modes is tolerant of the value of $d_{2}$, we adopted this value. Figure 4 shows the propagation losses of $\mathrm{TE}_{0}$ and $\mathrm{TE}_{2}$ modes against the thickness of the first cladding $d_{1}$. When the thickness $d_{1}$ is $0.08 \mu \mathrm{m}$, the loss of the $\mathrm{TE}_{0}$ mode is nearly equal to $0.1 \mathrm{~dB} / \mathrm{cm}$ and the loss of the $\mathrm{TE}_{2}$ mode is larger than $5 \mathrm{~dB} / \mathrm{cm}$. Therefore we designed $d_{1}$ to be $0.08 \mu \mathrm{m}$. This value of $\mathrm{TE}_{2}$-mode loss is not high enough to achieve practical single-mode propagation. However, since the coupling coefficient from the $\mathrm{TE}_{0}$ to the $\mathrm{TE}_{2}$ mode at the transformation region is small owing to the adiabatic transformation, a practical single-mode propagation is obtained.

We fabricated the spot size transformer under the optimum design. The tapered geometries of the core and the second cladding were formed by a shadowmask sputtering technique. ${ }^{6}$ The maximum tapered angle is approximately $8.7 \mathrm{mrad}(0.5 \mathrm{deg})$, and the length of the tapered portion is $3.5 \mathrm{~mm}$. This structure consists of only two materials. In this experiment, we used NA45 glass for the core and the second cladding and $\mathrm{SiO}_{2}$ for the other cladding layers. An antireflecting layer (thickness of $0.33 \mu \mathrm{m}$ ) was introduced into the waveguide having the smaller spot size to eliminate cladding modes. Figure 5 shows the measured results of the insertion loss and the spot size against the waveguide length. The spot size was calculated from the far-field pattern measurement in terms of the formula of Villuendas et al. ${ }^{8}$ The spot size was successfully transformed from 0.48 to $2.71 \mu \mathrm{m}$, which corresponds to a transformation ratio of 5.6. This value of transformation ratio is to our knowledge the largest value reported to date. The insertion loss of the transformation region was $0.9 \mathrm{~dB}$. Since the propagation loss of the waveguide is approximately $0.9 \mathrm{~dB} / \mathrm{cm}$, the transformation loss is evaluated to be smaller than $0.6 \mathrm{~dB}$.

In summary, we proposed a new spot size transformer using ARROW-B. This structure has a great advantage in that the spot size is precisely determined by controlling only the core thickness. The optimum design of this structure was achieved, and

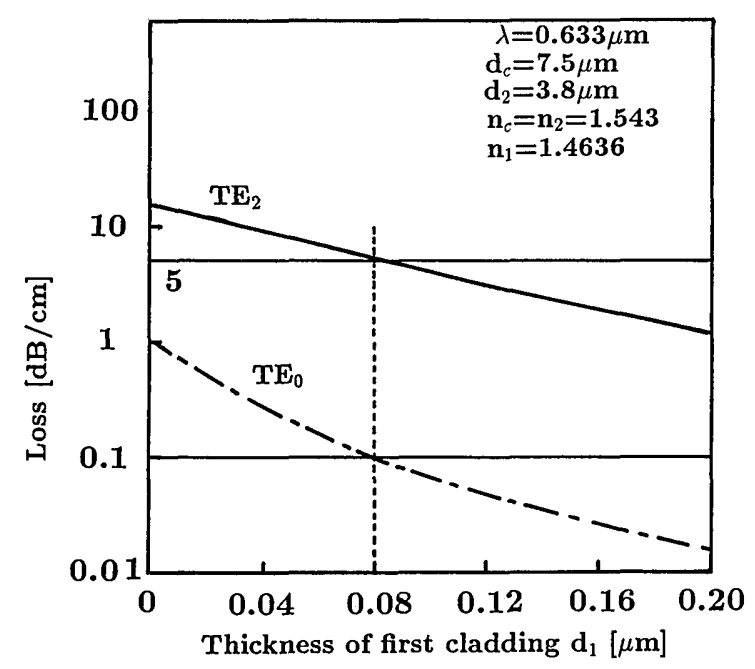

Fig. 4. Propagation losses of $\mathrm{TE}_{0}$ and $\mathrm{TE}_{2}$ modes versus the thickness of the first cladding layer of ARROW-B.

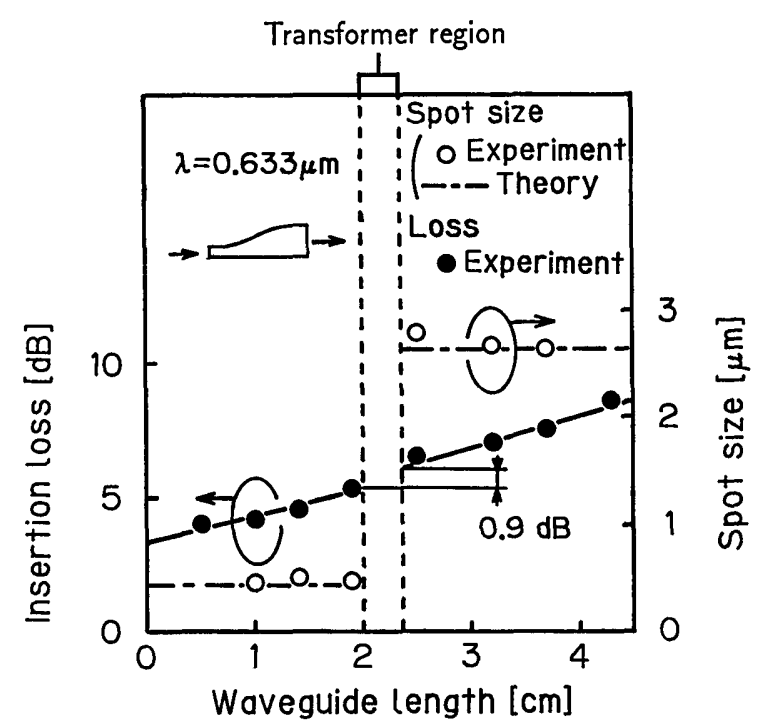

Fig. 5. Measured spot size and insertion loss versus the waveguide length. 
a transformation ratio of 5.6 and a small insertion loss of $0.9 \mathrm{~dB}$ were demonstrated.

This research was partly supported by the Matsuda Foundation.

\section{References}

1. K. Miura, I. Sawaki, and H. Nakajima, in Digest of Topical Meeting on Integrated and Guided-Wave Optics (Optical Society of America, Washington, D.C., 1988), paper MC3.

2. H. Yanagawa, S. Nakamura, and I. Ohyama, in Digest of Topical Meeting on Integrated Photonics Research (Optical Society of America, Washington, D.C., 1990), paper MI5.

3. H. Zhenguang, R. Srivastava, and R. V. Ramaswamy, IEEE J. Lightwave Technol. 7, 1590 (1989).

4. D. E. Bossi, W. D. Goodhue, L. M. Johnson, and R. H. Rediker, IEEE J. Quantum Electron. 27, 687 (1991).

5. T. L. Koch, U. Koren, G. Eisenstein, M. G. Young, M. Oron, C. R. Giles, and B. I. Miller, IEEE Photon. Technol. Lett. 2, 88 (1990).

6. N. Yamaguchi, Y. Kokubun, and K. Sato, IEEE J. Lightwave Technol. 8, 587 (1990).
7. T. Baba and Y. Kokubun, IEEE Photon. Technol. Lett. 1, 232 (1989).

8. F. Villuendas, F. Calvo, and J. V. Marqués, Opt. Lett. 12, 941 (1987). We calculated the spot size $w$ by using Villuendas et al.'s definition, given by

$$
w^{2}=\frac{\int_{-\infty}^{\infty}[f(x)]^{2} \mathrm{~d} x}{\int_{-\infty}^{\infty}\left[\frac{\mathrm{d} f(x)}{\mathrm{d} x}\right]^{2} \mathrm{~d} x},
$$

where $f(x)$ is the one-dimensional field distribution of the slab waveguide. Because the light power guided in ARROW-B is confined to the core strongly, the field distribution can be approximated by

$$
f(x)=\left\{\begin{array}{cl}
A \cos \left(\frac{\pi x}{d_{c}}\right) & |x| \leq d_{c} / 2 \\
0 & |x|>d_{c} / 2
\end{array},\right.
$$

where $d_{c}$ is the core thickness and $A$ is the amplitude. By substituting Eq. (2) into Eq. (1), we obtain the following relation:

$$
w=\frac{d_{\mathrm{c}}}{\pi}
$$

